\title{
Determination of the bioactive compounds, antioxidant activity and chemical composition of Brazilian blackberry, red raspberry, strawberry, blueberry and sweet cherry fruits
}

\author{
Vanessa Rios de Souza ${ }^{\text {a,* }}$, Patrícia Aparecida Pimenta Pereira ${ }^{\mathrm{b}}$, Thais Lomônaco Teodoro da Silva ${ }^{\mathrm{c}}$, \\ Luiz Carlos de Oliveira Lima ${ }^{\mathrm{d}}$, Rafael Pio ${ }^{\mathrm{e}}$, Fabiana Queiroz ${ }^{\mathrm{d}}$
}

a Science and Technology Institute, Federal University Vales of Jequitinhonha and Mucuri, 39100-000 Diamantina, MG, Brazil

${ }^{\mathrm{b}}$ Department of Food, Federal University of Ouro Preto, 35400-000 Ouro Preto, MG, Brazil

${ }^{\mathrm{c}}$ Department of Food Technology, School of Food Engineering, University of Campinas, 13083-862 Campinas, SP, Brazil

${ }^{\mathrm{d}}$ Department of Food Science, Federal University of Lavras, 37200-000 Lavras, MG, Brazil

e Department of Agriculture, Federal University of Lavras, 37200-000 Lavras, MG, Brazil

\section{A R T I C L E I N F O}

\section{Article history:}

Received 29 August 2013

Received in revised form 22 January 2014

Accepted 30 January 2014

Available online 13 February 2014

\section{Keywords:}

Bioactive compounds

Antioxidant activity

Berry

Cherry

\begin{abstract}
A B S T R A C T
This study aimed to evaluate the chemical composition, identify the bioactive compounds and measure the antioxidant activity present in blackberry, red raspberry, strawberry, sweet cherry and blueberry fruits produced in the subtropical areas of Brazil and to verify that the chemical properties of these fruit are similar when compared to the temperate production zones. Compared with berries and cherries grown in temperate climates, the centesimal composition and physical chemical characteristics found in the Brazilian berries and cherries are in agreement with data from the literature. For the mineral composition, the analyzed fruits presented lower concentrations of $\mathrm{P}, \mathrm{K}, \mathrm{Ca}, \mathrm{Mg}$ and $\mathrm{Zn}$ and higher levels of Fe. The values found for the bioactive compounds generally fit the ranges reported in the literature with minor differences. The greatest difference was found in relation to ascorbic acid, as all fruits analyzed showed levels well above those found in the literature.
\end{abstract}

(ㄷ) 2014 Elsevier Ltd. All rights reserved.

\section{Introduction}

Berry fruits, are small fleshy fruits, which are commercially cultivated and commonly consumed in fresh and processed forms, include blackberry (Rubus spp.), black raspberry (Rubus occidentalis), red raspberry (Rubus idaeus), blueberry (Vaccinium corymbosum) and strawberry (Fragaria $\times$ ananassa) (Seeram, 2008).

Berries are rich in phenolic compounds, such as phenolic acids, tannins, stilbenes, flavonoids and anthocyanins, but berries, in particular, have been the focus of considerable research regarding their anthocyanin-rich properties and according to Seeram (2008), there are many studies claim that that the dietary intake of berry fruits has a positive and profound impact on human health, performance, and disease.

\footnotetext{
* Corresponding author: Tel.: +55 353929 1391; fax: +55 3599480412.

E-mail addresses: vanessardsouza@gmail.com (V.R. de Souza), pattyap2001@ yahoo.com.br (P.A.P. Pereira), thais_tls@yahoo.com.br (T.L.T. da Silva), lcolima@ dca.ufla.br (L.C. de Oliveira Lima), rafaelpio@dag.ufla.br (R. Pio), fqueiroz@dca. ufla.br (F. Queiroz).
}

Although it is already well established that berries and cherries are sources of bioactive compounds such as polyphenols and anthocyanins, these studies focused mainly on berries from temperate climates, mainly in the temperate regions of Europe, Asia and North America (Chen, Xin, Zhang, \& Yuan, 2013). Knowing that the composition of the fruits varies with a series of factors that includes species, variety, cultivation, region, weather conditions, ripeness, time of harvest and storage conditions (Faniadis, Drogoudi, \& Vasilakakis, 2010; Haffner, Rosenfeld, Skrede, \& Wang, 2002), is extremely relevant for the characterization and comparison of berries produced in tropical and subtropical climates with traditional berries from a temperate climate.

The raspberry and blackberry cultivation in Brazil has been increasing steadily, especially in the subtropical areas where temperatures are higher in the fall and winter and especially higher in the summer, and previous results show that blackberry plants produce large quantities of fruit in subtropical areas, with some varieties producing higher amounts compared to temperate zones (Campagnolo \& Pio, 2012). For raspberries, the productive performance results of the subtropical areas in Brazil are very encouraging because the production of raspberries is constant throughout 
the year with certain cultivars producing large quantities of fruit in the fall and winter (Moura et al., 2012). Thus, the determination of the nutritional composition of the berries and cherries produced in Brazilian subtropical zones is important to know the nutritional and functional properties and to verify that the chemical properties of the fruit are similar when compared to the temperate production zones.

To this end, the aims of the present study were to evaluate the chemical composition, identify the bioactive compounds and measure the antioxidant activity present in blackberry (Rubus spp.), red raspberry ( $R$. idaeus), strawberry (Fragaria $\times$ ananassa), sweet cherry (Prunus avium L.) and blueberry (V. corymbosum) fruits produced in the subtropical areas of the states of Minas Gerais and São Paulo, Brazil.

\section{Materials and methods}

\subsection{Fruit samples}

The blackberry, red raspberry and strawberry plants were acquired from the south of Minas Gerais, whereas the blueberry and cherry plants were acquired from a producer in São Paulo. The fruits were harvested at their physiological maturity in the morning and transported in Styrofoam boxes to the post-harvest fruit and vegetable laboratory of the Universidade Federal de Lavras. Upon delivery, the fruits were sanitized, and all fruits were stored in a cold room at $-18{ }^{\circ} \mathrm{C}$ during the analysis time.

\subsection{Chemical reagents}

The following chemicals were used for the experiments described later: acetone, 2,2'-azino-bis(3-ethylbenzthiazoline-6sulphonic acid) (ABTS), aluminium chloride $\left(\mathrm{AlCl}_{3}\right), \beta$-carotene, (+)-catechin, hydrochloric acid $(\mathrm{HCl}), 2$,4-dinitrophenylhydrazine (2,4-DNPH), chloroform, copper sulphate, 2,2-diphenyl-1-picrylhydrazyl (DPPH), ethanol, ethyl ether, Folin-Ciocalteu reagent, gallic acid, 6-hydroxy-2,5,7,8-tetramethylchroman-2-carboxylic acid (Trolox), Kjeldahl reagent, linoleic acid, methanol, nitric acid, perchloric acid, petroleum ether, phenolphthalein solution, phosphate buffer, potassium sulphate, potassium persulphate, sodium carbonate, sodium nitrate $\left(\mathrm{NaNO}_{3}\right)$, sodium hydroxide $(\mathrm{NaOH})$, sulphuric acid and Tween 40 as well as the thermostable alpha-amylase, protease, and amyloglucosidase enzymes.

\subsection{Chemical analyses}

Three repetitions were performed for all chemical analyses. The values of the titratable acid, total soluble solids, total sugar, $\mathrm{pH}$, moisture, ash, protein, lipid, carbohydrate and total dietary fibre contents were determined (AOAC-Association of Official Analytical Chemists, 1998).

\subsection{Minerals}

The mineral levels were assessed in crushed and homogenized samples prepared by organic wet digestion in accordance with the methodology described by Salinas and Garcia (1985). For organic digestion, the samples were treated with a mixture of concentrated nitric and perchloric acids at a high temperature. The macro- and microelements were solubilized, subjected to different treatments and diluted for further quantitative evaluation. The quantification of elements was performed by spectrophotometry using a standard curve for each mineral. To determine the concentration of calcium, iron and manganese, we used an atomic absorption spectrophotometer and acetylene. A flame photometer was used to determine potassium (768 nm), and a visible-light spectrophotometer was used to determine phosphorus (420 nm).

\subsection{Preparation of antioxidant and phenolic extracts}

The extracts were obtained according to the method described by Larrauri, Ruperez, and Saura-Calixto (1997). Briefly, samples were weighed (in grams) in centrifuge tubes and extracted sequentially with $40 \mathrm{~mL}$ of methanol/water (50:50, v/v) at room temperature for $1 \mathrm{~h}$. The tubes were centrifuged at $25,400 \mathrm{~g}$ for $15 \mathrm{~min}$, and the supernatant was recovered. Then, $40 \mathrm{~mL}$ of acetone/water $(70: 30, v / v)$ was added to the residue at room temperature. The samples were extracted for $60 \mathrm{~min}$ and centrifuged. To determine the antioxidant activity as well as total flavonoid, total monomeric anthocyanin and phenolic contents, the methanol and acetone extracts were combined and brought to a final volume of $100 \mathrm{~mL}$ with distilled water.

\subsubsection{Antioxidant activity}

The antioxidant activity was determined using the ABTS, DPPH and $\beta$-carotene methods. For the ABTS assay, the procedure followed the method of Re et al. (1999) with minor modifications. The ABTS radical cation (ABTS•+) was generated by the reaction of $5 \mathrm{~mL}$ of aqueous ABTS solution $(7 \mathrm{mM})$ with $88 \mu \mathrm{L}$ of $140 \mathrm{mM}$ (2.45 mM final concentration) potassium persulphate. The mixture was kept in the dark for $16 \mathrm{~h}$ before use and then diluted with ethanol to obtain an absorbance of $0.7 \pm 0.05$ units at $734 \mathrm{~nm}$ using a spectrophotometer. The fruit extracts $(30 \mu \mathrm{L})$ or a reference substance (Trolox) were allowed to react with $3 \mathrm{~mL}$ of the resulting blue-green ABTS radical solution in the dark. The decrease of absorbance at $734 \mathrm{~nm}$ was measured after 6 min. Ethanolic solutions of known Trolox concentrations were used for calibration. The results are expressed as micromoles of Trolox equivalents (TEs) per gram of fresh weight ( $\mu \mathrm{mol}$ of TEs/g of f.w.).

The DPPH free radical-scavenging capacity was estimated using the method of Brand-williams, Cuvelier, and Berset (1995). Briefly, the solution of DPPH $(600 \mu \mathrm{M})$ was diluted with ethanol to obtain an absorbance of $0.7 \pm 0.02$ units at $517 \mathrm{~nm}$. The fruit extracts $(0.1 \mathrm{~mL})$ were allowed to react with $3.9 \mathrm{~mL}$ of the DPPH radical solution for $30 \mathrm{~min}$ in the dark, and the decrease in absorbance from the resulting solution was monitored. The absorbance of the reaction mixture was measured at $517 \mathrm{~nm}$. The results were expressed as $\mathrm{EC}_{50}$ (g f.w./g of DPPH).

The antioxidant activity was also determined by the $\beta$-carotene method, following the procedure described by Marco (1968) with minor modifications. Briefly, an aliquot $(50 \mu \mathrm{L})$ of the $\beta$-carotene chloroform solution $(20 \mathrm{mg} / \mathrm{mL})$ was added to a flask containing $40 \mu \mathrm{L}$ of linoleic acid, $1.0 \mathrm{~mL}$ of chloroform, and $530 \mu \mathrm{L}$ of Tween 40 and then mixed. The chloroform was evaporated using an oxygenator. After the evaporation, oxygenated distilled water (approximately $100 \mathrm{~mL}$ ) was added to obtain an absorbance of $0.65 \pm 0.5$ units at $470 \mathrm{~nm}$. An aliquot $(0.4 \mathrm{~mL})$ of Trolox solution $(200 \mathrm{mg} / \mathrm{L})$ or diluted fruit extract $(200 \mathrm{mg} / \mathrm{L})$ was added to $5 \mathrm{~mL}$ of the $\beta$-carotene solution and incubated in a water bath at $40^{\circ} \mathrm{C}$. The measurements were performed after $2 \mathrm{~min}$ and $120 \mathrm{~min}$ at an absorbance of $470 \mathrm{~nm}$ using a spectrophotometer. The antioxidant activity was calculated as the percent inhibition relative to the control.

\subsubsection{Total phenolic content}

The total phenolic content was determined according to the adapted Folin-Ciocalteu method (Waterhouse, 2002). The extracts $(0.5 \mathrm{~mL})$ were mixed with $2.5 \mathrm{~mL}$ of Folin-Ciocalteu reagent $(10 \%)$ and $2 \mathrm{~mL}$ of sodium carbonate solution (4\%). The mixture was stirred and kept at room temperature for $2 \mathrm{~h}$ in the dark. The absorbance was measured at $750 \mathrm{~nm}$ against a blank. Aqueous 
solutions of gallic acid were used for calibration. The results are expressed as g gallic acid equivalents (GAE)/100 g.

\subsubsection{Total flavonoid content}

The total flavonoid content was measured by the aluminium chloride colorimetric assay (Zhishen, Mengcheng, \& Jianming, 1999). An aliquot (1 mL) of extract or catechin standard solution $(5,10,25,50,100,150$ or $200 \mathrm{mg} / \mathrm{L})$ was added to a $10 \mathrm{~mL}$ volumetric flask containing $4 \mathrm{~mL}$ of water. To the flask, $0.3 \mathrm{~mL}$ of $5 \%$ $\mathrm{NaNO}_{2}$ and $0.3 \mathrm{~mL}$ of $10 \% \mathrm{AlCl}_{3}$ were added. After $6 \mathrm{~min}, 2 \mathrm{~mL}$ of $1 \mathrm{M} \mathrm{NaOH}$ was added and the total volume was brought to $10 \mathrm{~mL}$ by the addition of $\mathrm{H}_{2} \mathrm{O}$. The solution was mixed and the absorbance was measured against a prepared blank reagent at $510 \mathrm{~nm}$. The total flavonoid contents of the fruits were expressed as $\mathrm{mg}$ catechin equivalents (CE)/100 g of f.w. The samples were analyzed in triplicate.

\subsubsection{Total monomeric anthocyanin content}

The total monomeric anthocyanin content (TMAC) was estimated using the $\mathrm{pH}$ differential method (Wrolstad, 1976). Briefly, each fruit extract was diluted with $\mathrm{pH} 1.0$ and $\mathrm{pH} 4.5$ buffers to attain the same dilution. The absorbance was measured at $510 \mathrm{~nm}$ and $700 \mathrm{~nm}$ in both $\mathrm{pH} 1.0$ and $\mathrm{pH} 4.5$ buffers. Then, the TMAC (expressed in terms of cyanidin-3-glucoside) was calculated using the following formula:

$A=\left(A_{510}-A_{700}\right)_{\mathrm{pH} 1.0}-\left(A_{510}-A_{700}\right)_{\mathrm{pH} 4.5}$

TMA content $=(A \times \mathrm{MW} \times \mathrm{DF} \times \mathrm{Ve} \times 1000) /(\varepsilon \times 1 \times M)$

where MW is the molecular weight of cyanidin-3-glucoside ( $449 \mathrm{~g} \mathrm{~mol}^{-1}$ ), DF is the dilution factor, Ve is the extract volume, $\varepsilon$ is the molar extinction coefficient of cyanidin-3-glucoside $(29,600)$, and $M$ is the mass of the berries extracted.

The results were expressed as mg cyanidin-3-glucoside equivalents/100 g of f.w.

\subsection{Ascorbic acid}

The vitamin $\mathrm{C}$ content of each fruit pulp was determined by a colorimetric method with 2,4-dinitrophenylhydrazine (2,4-DNPH) according to Strohecker and Henning (1967). The samples were analyzed in a spectrophotometer at an absorbance of $520 \mathrm{~nm}$. The results are expressed as $\mathrm{mg}$ ascorbic acid/100 $\mathrm{g}$ of fresh weight.

\subsection{Statistical analysis}

The data were reported as the means \pm the standard deviation (SD) experiments run in triplicate and were analyzed using SPSS 17.0. A Pearson correlation test was conducted to determine the correlation between variables. Significance levels were defined $p<0.05$.

\section{Results and discussion}

Table 1 presents the centesimal composition of blackberry, red raspberry, strawberry, blueberry and sweet cherry fruits and compares the composition listed in the National Nutrient Database for Standard Reference (USDA - United States Department of Agriculture, 2013) to these fruits.

All fruits had high moisture content, ranging from $86.43 \%$ (cherry) to $92.68 \%$ (strawberry). The protein content ranged from $0.48 \%$ (blueberry) to $1.27 \%$ (blackberry). All fruits were low in fat content; the blueberry had the lowest fat content $(0.19 \%)$ and the blackberry had the highest $(0.42 \%)$. The carbohydrate content ranged from $6.30 \%$ (strawberry) to $11.94 \%$ (cherry). Regarding dietary fibre, the levels were between $1.31 \%$ (strawberry) and $5.77 \%$ (red raspberry). The ash ranged from $0.08 \%$ (blueberry) to $0.42 \%$ (cherry). Based on these results, the energy value was found to range from $29.4 \mathrm{kcal}$ (strawberry) to $49.57 \mathrm{kcal}$ (blackberry).

In general, the Brazilian berries and cherry showed similar centesimal composition to the database values provided by the USDA with slightly higher moisture content and slightly lower energy, protein, lipid, carbohydrate and dietary fibre values. Thus, although the climate, soil, management, insolation and others conditions were different, these differences may not significantly affect the composition of these fruits.

Table 2 presents the physical-chemical characteristics of blackberry, red raspberry, strawberry, blueberry and sweet cherry fruits. The range of values found in the literature is also presented.

The $\mathrm{pH}$ values ranged from 2.86 to 4.08 (red raspberry and cherry, respectively), and the levels of acidity ranged from $0.55 \mathrm{~g}$ of citric acid/100 $\mathrm{g}$ in the cherry to $1.88 \mathrm{~g}$ of citric acid/100 $\mathrm{g}$ in the red raspberry. With respect to total soluble solids and total sugars, the blackberry had the lowest levels $\left(10.17{ }^{\circ}\right.$ Brix and $4.47 \%$, respectively) and cherry had the highest levels (18.67 ${ }^{\circ}$ Brix and $13.73 \%$, respectively). Among the fruits analyzed, the blueberry and the cherry stand out for presenting the highest levels of total soluble solids and sugars and the lowest levels of acidity; consequently, they have the highest ratios of total soluble solids/acid (28.61 to blueberry and 34.07 to cherry).

In general, the physical-chemical characteristics found for the Brazilian berries are in agreement with the literature. However, the variation between the characteristics presented in this paper and the previously published data can be explained by the influence of the cultivar, time of harvest, maturity, ripening stage, weather and soil conditions, sun exposure, location of fruit on the plant and post-harvest handling on the chemical and physical characteristics of the fruit (Faniadis et al., 2010).

The mineral compositions, including $\mathrm{P}, \mathrm{K}, \mathrm{Ca}, \mathrm{Mg}, \mathrm{Zn}$ and $\mathrm{Fe}$, of blackberry, red raspberry, strawberry, blueberry and sweet cherry fruits are shown in Table 3. The mineral contribution of each fruit to the Dietary Reference Intake (DRI) for a healthy adult male in\% per $100 \mathrm{~g}$ of pulp (Institute of Medicine, 1999-2011) and the literature range of these values are also presented in Table 3.

Among the fruits analyzed, the concentration of minerals (measured in $\mathrm{mg} / 100 \mathrm{~g}$ f.w.) was found to range between 5.70 (red raspberry) and 12.21 (cherry) for P; 51.24 (strawberry) and 90.92 (cherry) for $\mathrm{K} ; 0.00$ (blueberry and cherry) and 7.25 (blackberry) for Ca; 4.92 (blueberry) and 15.96 (red raspberry) for $\mathrm{Mg} ; 0.13$ (strawberry and blueberry) and 0.69 (cherry) for $\mathrm{Zn}$; and 1.00 (strawberry) and 1.28 (blackberry) for Fe.

In comparison to the USDA database and data from the literature, the analyzed fruits presented lower concentrations of the minerals P, K, Ca, Mg and $\mathrm{Zn}$ and higher levels of Fe. This difference is justified because, as already mentioned, we compared the composition of fruits of different cultivars subjected to different climatic conditions and post-harvest handling techniques. In studies of the effects of cultivars and cultivation conditions on the composition of strawberries, Hakala, Lapvetelainen, Houpalahti, Kallio, and Tahvonen (2003) analyzed several cultivars of strawberries for two consecutive years and concluded that the cultivar and, to a lesser extent, the climatic conditions and soil influenced the mineral composition of the strawberries. The soils of temperate regions such as Europe, are typically basic, since the soils of Brazil are typically acidic, with low levels of P, Ca, K and $\mathrm{Mg}$ and high contents of $\mathrm{Al}, \mathrm{Mn}$ and Fe (Santos et al., 2006); fact that can justify the results.

In general, the fruits analyzed do not significantly contribute to the DRI of Ca, P or K, but have a significant contribution to the DRI of Fe and an intermediate contribution to the DRI for $\mathrm{Zn}$ and $\mathrm{Mg}$. 
Table 1

The composition ( $\mathrm{g} / 100 \mathrm{~g}$ fresh weight) of blackberry, red raspberry, strawberry, blueberry and cherry and the USDA database.

\begin{tabular}{|c|c|c|c|c|c|}
\hline & \multicolumn{5}{|l|}{ Fruits } \\
\hline & Blackberry & Red raspberry & Strawberry & Blueberry & Cherry \\
\hline Moisture & $87.92 \pm 0.59$ & $88.60 \pm 0.19$ & $92.68 \pm 0.17$ & $87.70 \pm 0.14$ & $86.43 \pm 0.31$ \\
\hline USDA database & 88.15 & 85.75 & 90.95 & 84.21 & 82.25 \\
\hline Protein & $1.27 \pm 0.06$ & $1.00 \pm 0.08$ & $0.50 \pm 0.02$ & $0.48 \pm 0.01$ & $1.00 \pm 0.05$ \\
\hline USDA database & 1.39 & 1.20 & 0.67 & 0.74 & 1.06 \\
\hline Lipids & $0.42 \pm 0.05$ & $0.28 \pm 0.02$ & $0.25 \pm 0.02$ & $0.19 \pm 0.01$ & $0.20 \pm 0.01$ \\
\hline USDA database & 0.49 & 0.65 & 0.30 & 0.33 & 0.20 \\
\hline Carbohydrates & $10.18 \pm 0.61$ & $9.88 \pm 0.11$ & $6.30 \pm 0.13$ & $11.54 \pm 0.13$ & $11.94 \pm 0.28$ \\
\hline USDA database & 9.61 & 11.94 & 7.68 & 14.49 & 16.01 \\
\hline Dietary fibre & $4.47 \pm 0.67$ & $5.77 \pm 0.57$ & $1.31 \pm 0.18$ & $1.90 \pm 0.46$ & $2.07 \pm 0.22$ \\
\hline USDA database & 5.30 & 6.50 & 2.0 & 2.40 & 2.10 \\
\hline Ash & $0.21 \pm 0.02$ & $0.25 \pm 0.00$ & $0.27 \pm 0.01$ & $0.08 \pm 0.00$ & $0.42 \pm 0.01$ \\
\hline USDA database & - & - & - & - & - \\
\hline Energy value (kcal) & $49.57 \pm 2.18$ & $46.00 \pm 0.85$ & $29.4 \pm 0.75$ & $49.86 \pm 0.59$ & $53.59 \pm 1.22$ \\
\hline USDA database & 43 & 52 & 32 & 57 & 63 \\
\hline
\end{tabular}

Mean value \pm standard deviation of fruit weight; $n=3$.

Table 2

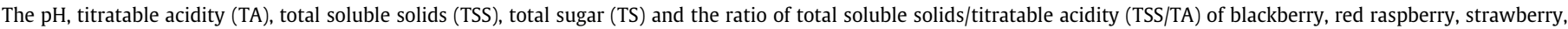
blueberry and cherry.

\begin{tabular}{|c|c|c|c|c|c|}
\hline & \multicolumn{5}{|l|}{ Fruits } \\
\hline & Blackberry $^{\mathrm{a}}$ & Red raspberry ${ }^{\mathrm{b}}$ & Strawberry $^{\mathrm{c}}$ & Blueberry $^{\mathrm{d}}$ & Cherry $^{\mathrm{e}}$ \\
\hline $\mathrm{pH}$ & $2.99 \pm 0.04$ & $2.86 \pm 0.04$ & $3.73 \pm 0.01$ & $3.64 \pm 0.05$ & $4.08 \pm 0.01$ \\
\hline Literature & $2.51-4.12$ & $3.11-3.65$ & $3.27-3.43$ & $2.56-3.15$ & $3.11-4.81$ \\
\hline $\mathrm{TA} /(\mathrm{g}$ citric acid/100 g) & $1.51 \pm 0.04$ & $1.88 \pm 0.09$ & $0.86 \pm 0.10$ & $0.58 \pm 0.07$ & $0.55 \pm 0.07$ \\
\hline Literature & $1.26-1.54$ & $0.62-3.59$ & $0.60-1.31$ & $0.68-0.84$ & $0.57-2.53$ \\
\hline TSS ( ${ }^{\circ}$ Brix) & $10.17 \pm 0.29$ & $10.33 \pm 0.58$ & $10.50 \pm 0.50$ & $14.67 \pm 0.58$ & $18.67 \pm 0.58$ \\
\hline Literature & $6.19-11.11$ & $8.4-14.7$ & $6.33-10.86$ & $10.67-13.2$ & $12.5-22.73$ \\
\hline TS (\%) & $4.47 \pm 1.35$ & $6.38 \pm 1.71$ & $5.08 \pm 0.39$ & $12.74 \pm 1.06$ & $13.73 \pm 1.01$ \\
\hline Literature & $2.75-22.1$ & $2.62-9.24$ & $4.50-6.52$ & 9.96 & $7.68-14.40$ \\
\hline TSS/TA & $6.71 \pm 0.18$ & $5.50 \pm 0.55$ & $12.27 \pm 1.39$ & $28.61 \pm 6.27$ & $34.07 \pm 3.85$ \\
\hline
\end{tabular}

Mean value \pm standard deviation of pulp weight; $n=3$.

a Literature data for blackberry: Hassimotto, Mota, Cordenunsi, and Lajolo (2008), Tosun, Ustun, and Tekguler (2008), Acosta-Montoya et al. (2010), Wu et al. (2010).

b Literature data for red raspberry: Haffner et al. (2002), Çekiç and Ozgen (2010), Moura et al. (2012).

c Literature data for strawberry: Kafkas, Kosar, Paydas, Kafkas, and Baser (2007).

${ }^{\mathrm{d}}$ Literature data for blueberry: Almenar, Samsudin, Auras, Harte, and Rubino (2008).

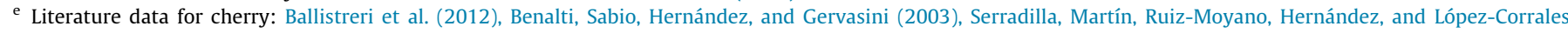
(2012), Faniadis et al. (2010), Serradilla et al. (2011), USDA (2013).

Table 3

The minerals contents and the \%DRI contribution per $100 \mathrm{~g}$ of pulp of blackberry, red raspberry, strawberry, blueberry and cherry.

\begin{tabular}{|c|c|c|c|c|c|}
\hline & Blackberry & Red raspberry & Strawberry & Blueberry & Cherry \\
\hline $\mathrm{P}(\mathrm{mg} / 100 \mathrm{~g}$ f.w. $)$ & $7.25 \pm 0.35$ & $5.70 \pm 0.10$ & $6.59 \pm 0.16$ & $8.61 \pm 0.10$ & $12.21 \pm 0.28$ \\
\hline $\mathrm{DRI}^{\mathrm{a}}$ & 1.25 & 0.98 & 1.14 & 1.48 & 2.10 \\
\hline Literature $^{\mathrm{b}}$ & $12.00-29.00$ & & & & \\
\hline $\mathrm{K}$ (mg/100 g f.w.) & $79.73 \pm 3.87$ & $71.84 \pm 1.22$ & $51.24 \pm 1.21$ & $70.13 \pm 0.81$ & $90.92 \pm 2.06$ \\
\hline $\mathrm{DRI}^{\mathrm{a}}$ & 1.70 & 1.53 & 1.09 & 1.49 & 1.93 \\
\hline Literature $^{\mathrm{b}}$ & $77.00-349.79$ & & & & \\
\hline Ca (mg/100 g f.w.) & $7.25 \pm 0.35$ & $1.14 \pm 0.02$ & $2.20 \pm 0.05$ & $0.00 \pm 0.00$ & $0.00 \pm 0.00$ \\
\hline $\mathrm{DRI}^{\mathrm{a}}$ & 0.91 & 0.14 & 0.27 & 0.00 & 0.00 \\
\hline Literature $^{\mathrm{b}}$ & $6.00-29.00$ & & & & \\
\hline $\mathrm{Mg}$ (mg/100 g f.w.) & $15.70 \pm 0.76$ & $15.96 \pm 0.27$ & $8.78 \pm 0.21$ & $4.92 \pm 0.06$ & $12.21 \pm 0.28$ \\
\hline $\mathrm{DRI}^{\mathrm{a}}$ & 4.49 & 4.56 & 2.51 & 1.41 & 3.49 \\
\hline Literature $^{\mathrm{b}}$ & $6.00-44.80$ & & & & \\
\hline $\mathrm{Zn}(\mathrm{mg} / 100 \mathrm{~g}$ f.w. $)$ & $0.20 \pm 0.01$ & $0.37 \pm 0.01$ & $0.13 \pm 0.00$ & $0.13 \pm 0.00$ & $0.69 \pm 0.02$ \\
\hline $\mathrm{DRI}^{\mathrm{a}}$ & 2.13 & 3.94 & 1.38 & 1.38 & 7.34 \\
\hline Literature $^{\mathrm{b}}$ & $0.07-0.44$ & & & & \\
\hline Fe (mg/100 g f.w.) & $1.28 \pm 0.066$ & $1.06 \pm 0.02$ & $1.00 \pm 0.02$ & $1.24 \pm 0.01$ & $1.16 \pm 0.03$ \\
\hline $\mathrm{DRI}^{\mathrm{a}}$ & 21.33 & 17.67 & 16.67 & 20.67 & 19.33 \\
\hline Literature $^{\mathrm{b}}$ & $0.28-1.08$ & & & & \\
\hline
\end{tabular}

a Institute of Medicine (1999-2011).

b Literature: USDA (2013), Hakala et al. (2003), Tosun et al. (2008).

The results for the total phenolic, total flavonoid, total monomeric anthocyanin and ascorbic acid contents as well as the antioxidant capacity of blackberry, red raspberry, strawberry, blueberry and cherry fruits are shown in Table 4 . The range found for the total phenolic compounds, anthocyanin and ascorbic acid contents, which are the bioactive compounds most often found 
Table 4

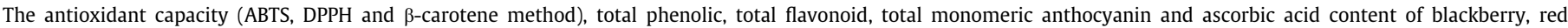
raspberry, strawberry, blueberry and cherry.

\begin{tabular}{|c|c|c|c|c|c|}
\hline & \multicolumn{5}{|l|}{ Fruits } \\
\hline & Blackberry $^{\mathrm{a}}$ & Red raspberry ${ }^{\mathrm{b}}$ & Strawberry ${ }^{\mathrm{c}}$ & Blueberry $^{\mathrm{d}}$ & Cherry $^{\mathrm{e}}$ \\
\hline Antioxidant capacity - ABTS ( $\mu \mathrm{mol} / \mathrm{g}$ f.w.) & $13.23 \pm 1.37$ & $6.27 \pm 0.02$ & $7.87 \pm 0.87$ & $5.88 \pm 1.17$ & $8.83 \pm 1.32$ \\
\hline Antioxidant capacity - DPPH (EC ${ }_{50}-$ g f.w./g DPPH) & $2142.42 \pm 125.64$ & $4960.58 \pm 157.33$ & $3778.94 \pm 333.88$ & $7775.45 \pm 1009.60$ & $6065.68 \pm 563.46$ \\
\hline Antioxidant capacity - $\beta$-carotene (\% protection) & $87.46 \pm 3.09$ & $75.19 \pm 3.92$ & $67.13 \pm 0.42$ & $59.88 \pm 1.06$ & $61.93 \pm 0.83$ \\
\hline Total phenolics (mg GAEs/100 g f.w.) & $850.52 \pm 4.77$ & $357.83 \pm 7.06$ & $621.92 \pm 15.51$ & $305.38 \pm 5.09$ & $314.45 \pm 5.95$ \\
\hline Literature & $176-1020$ & $148-714$ & $200-300$ & $44.4-394$ & $74-501.58$ \\
\hline Total flavonoid (mg CE/100 g f.w.) & $87.03 \pm 4.85$ & $9.61 \pm 2.15$ & $38.17 \pm 2.76$ & $47.53 \pm 2.40$ & $59.92 \pm 3.76$ \\
\hline $\begin{array}{l}\text { Total anthocyanin (mg of cyanidin 3-glucoside equivalent/100 g } \\
\text { of f.w.) }\end{array}$ & $58.61 \pm 2.19$ & $14.69 \pm 2.03$ & $16.03 \pm 0.50$ & $29.72 \pm 4.20$ & $26.72 \pm 3.22$ \\
\hline Literature & $77-188$ & $1.3-437$ & $20-32$ & $140-224$ & $6-85$ \\
\hline Ascorbic acid (mg/100 g f.w.) & $52.41 \pm 11.31$ & $92.17 \pm 10.11$ & $90.13 \pm 2.24$ & $73.21 \pm 0.35$ & $62.42 \pm 7.69$ \\
\hline Literature & $10-17$ & $15-38$ & $32-85$ & 10 & $7-103$ \\
\hline
\end{tabular}

Mean value \pm standard deviation of fruit weight; $n=3$.

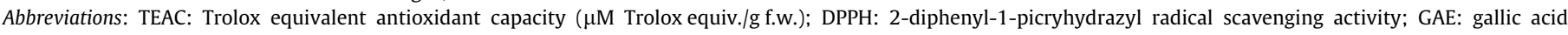
equivalent; $\mathrm{CE}$ : catechin equivalent.

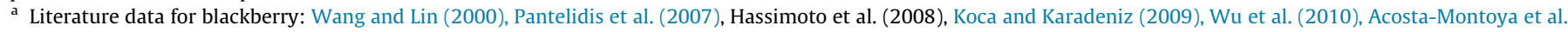
(2010), Samec and Zegarac (2011).

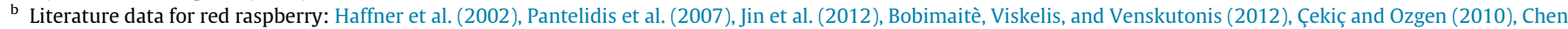
et al. (2013).

c Literature data for strawberry: Wang and Lin (2000), Hakala et al. (2003), Pantelidis et al. (2007).

d Literature data for blueberry: Koca and Karadeniz (2009), You et al. (2011).

e Literature data for cherry: Benalti et al. (2003), Pantelidis et al. (2007), Faniadis et al. (2010), Samec and Zegarac (2011), Serradilla et al. (2011), Ballistreri et al. (2012), Serradilla et al. (2012), USDA (2013).

in the literature, are also expressed in Table 4. We chose not to include the literature values for antioxidant activity due to the differences between the methods and the presentation of the results, which did not allow for a proper comparison. Additionally, because data found for the flavonoids were not abundant in the literature, these parameters was also not expressed.

In general, the antioxidant methods utilized are in agreement; the blackberry has the highest antioxidant activity, the strawberry the intermediate and the blueberry the lowest. The descending order of antioxidant capacity of the fruits for each antioxidant method used is:

ABTS method: Blackberry $>$ Cherry $>$ Strawberry $>$ Red Raspberry $>$ Blueberry.

DPPH method: Blackberry $>$ Strawberry $>$ Red Raspberry $>$ Cherry > Blueberry.

$\beta$-Carotene method: Blackberry $>$ Red Raspberry $>$ Strawberry $>$ Cherry > Blueberry.

According to Hassimoto, Genovese, and Lajolo (2005), one of the major problems with the antioxidant activity of biological materials is the choice of the method of analysis because typically the analysis is specific for only one property. The three methods used presented coherent results for the fruits evaluated, which was mainly seen with the DPPH and $\beta$-carotene methods. The ABTS, $\mathrm{DPPH}, \beta$-carotene methods all show that the blackberry is the richest source of antioxidants and the blueberry is the poorest.

According to Hassimoto et al. (2005), the values of antioxidant activity are classified as high ( $>70 \%$ inhibition), intermediate (40$70 \%$ inhibition), and low ( $<40 \%$ inhibition). According to this classification, blackberries and red raspberries are good sources of antioxidants and the other fruits (strawberry, cherry and blueberry) have intermediate antioxidant activity. The red raspberry and the cherry antioxidant activity (TEAC and DPPH) is in agreement with the range found in the literature (Çekiç \& Ozgen, 2010; Jin et al., 2012).

The total phenolic content ranged from 305.38 (blueberry) to $850.52 \mathrm{mg} \mathrm{GAE} / 100 \mathrm{~g}$ (blackberry). Following the polyphenol classification proposed by Vasco, Ruales, and Kamal-Eldin (2008) using low ( $<100 \mathrm{mg} \mathrm{GAE} / 100 \mathrm{~g}$ ), medium (100-500 mg GAE/100 g) and high ( $>500 \mathrm{mg} \mathrm{GAE} / 100 \mathrm{~g}$ ) denominations, the blackberry (850.52 mg GAE/100 g) and the strawberry (621.92 mg GAE/ $100 \mathrm{~g}$ ) can be categorized as having a high concentration of phenols. This classification indicates that this fruit is an excellent source of phenols. Red raspberries (357.82 mg GAE/100 g), blueberries (305.38 $\mathrm{mgGAE} / 100 \mathrm{~g}$ ) and cherries (314.45 mg GAE/ $100 \mathrm{~g}$ ) can be categorized as having an average phenol content, and they may also be considered a good source of phenols. According to the data from the literature for berries and cherries, the blackberry, raspberry, blueberry and cherry all showed phenolic contents consistent with ranges previously reported. Additionally, the phenolic content of the strawberry was higher than that reported in the literature (Table 4).

The total flavonoids ranged from 9.61 (red raspberry) to $87.03 \mathrm{mg} \mathrm{CE} / 100 \mathrm{~g}$ (blackberry), with the cherry (59.92 mg CE/100 g), blueberry (47.53 mg CE/100 g) and strawberry (38.17 mg CE/100 g) presenting the intermediate values. Compared to literature data, the blackberry ( $87.03 \mathrm{mg} \mathrm{CE} / 100 \mathrm{~g}$ ) had higher levels than those found by Samec and Zegarac (2011) (66.13 mg CE/100 g).

For the total monomeric anthocyanin contents, the blackberry presented the highest value $(58.61 \mathrm{mg}$ of cyanidin 3-glucoside equivalent/g), the blueberry and cherry presented the intermediate values (29.72 and $26.72 \mathrm{mg}$ of cyanidin 3-glucoside equivalent/g, respectively) and the red raspberry showed the lowest value (14.69 mg of cyanidin 3-glucoside equivalent/g). The blackberry, strawberry and blueberry anthocyanin contents were lower than those found in the literature, and the raspberry and cherry were within the range previously found (Table 4). Compared with blackberries grown in temperate climates, the tropical blackberry presents a lower anthocyanin content (Acosta-Montoya et al., 2010).

The ascorbic acid levels ranged from 52.41 (blackberry) to $92.17 \mathrm{mg} / 100 \mathrm{~g}$ f.w. (red raspberry). Ramful, Tarnus, Aruoma, Bourdan, and Bahorun (2011) classified fruits into three categories according to the ascorbic acid content: low ( $<30 \mathrm{mg} / 100 \mathrm{~g})$, medium $(30-50 \mathrm{mg} / 100 \mathrm{~g})$ and high $(>50 \mathrm{mg} / 100 \mathrm{~g})$. According to this classification, all fruits analyzed qualify as fruits with high ascorbic acid content because all berries fruits analyzed exhibited ascorbic 
Table 5

Pearson's correlation coefficients $(p<0.05)$ between antioxidant capacity parameters, total phenolic contents, total flavonoid, total monomeric anthocyanin and ascorbic acid.

\begin{tabular}{llllllll}
\hline & \multicolumn{7}{l}{ Antioxidant } \\
\cline { 2 - 7 } & TEAC & DPPH & $\beta$-Carot. & TPC & TFC & TMA & AA \\
\hline TEAC & - & - & - & 0.83 & - & 0.85 & - \\
DPPH & - & - & -0.86 & 0.91 & 0.84 & - & - \\
$\beta$-Carot. & - & -0.86 & - & - & - & - & - \\
TPC & 0.83 & 0.91 & - & - & - & - & - \\
TFC & 0.84 & - & - & - & - & 0.89 & -0.93 \\
TMA & 0.85 & - & - & - & 0.89 & - & -0.88 \\
AA & - & - & - & - & -0.93 & -0.88 & - \\
\hline
\end{tabular}

Abbreviations: TEAC: Trolox equivalent antioxidant capacity; DPPH: 2-diphenyl-1picryhydrazyl radical scavenging activity; $\beta$-carot: $\beta$-carotene method; TPC: total phenolic contents; TF: total flavonoid contents; TMA: total monomeric anthocyanin; AA: ascorbic acid.

acid contents well above the ranges found in the literature (Table 4).

The production of bioactive compounds is realized at the level of secondary metabolism which in turn is a function of gene expression. The production of bioactive compounds then depends of the genetic factor and at the same time depends of the environmental factors, once this can modify the production of secondary metabolites directly influencing the genes expression (Sharapin, 2000).

The climate conditions, the soil composition and the management of berries are the mainly factors that may by explain the difference of bioactive compounds. The subtropical climate in Brazil is characterized by average annual temperatures below $21^{\circ} \mathrm{C}$, where summer is mild and winter is colder. Although the difference of the average annual temperatures compared with the temperate regions of Europe, Asia and North America, the sun incidence is larger and rainfall index is generally higher.

It is also important to emphasize that the difference found in our results and previously reported papers should also be explained by the various extraction methods applied in previous methods.

The Pearson's correlation coefficients between antioxidant activity, total phenolic contents and ascorbic acid levels are presented in Table 5.

The total antioxidant capacity from the TEAC and DPPH tests was highly and positively correlated to total phenolic contents. The total antioxidant capacity (TEAC) was also highly and positively correlated total monomeric anthocyanin contents and DPPH to the total flavonoid contents. Several studies with berries and cherries have reported relationships between the antioxidant activity and the phenolic compounds and anthocyanin contents (Hassimoto, Mota, Cordenunsi, \& Lajolo, 2008; Koca \& Karadeniz, 2009; Pantelidis, Vasilakakis, Manganaris, \& Diamantidis, 2007; Wu, Frei, Kennedy, \& Zhao, 2010).

The total flavonoid content was highly and positively correlated to the total monomeric anthocyanin content, and both of these parameters were highly and negatively correlated to the ascorbic acid content. Anthocyanins belong to a class of flavonoids that are the water-soluble pigments responsible for the orange, red and blue colors of many fruits (Hassimoto et al., 2008); therefore, one would expect this strong correlation between the flavonoids and anthocyanins.

\section{Conclusion}

The blackberry stands out among the fruits evaluated by exhibiting the highest antioxidant activity and the highest levels of phenols, flavonoids, anthocyanins and carotenoids. Compared with berries and cherries grown in temperate climates, the centesimal composition and physical chemical characteristics found in the Brazilian berries and cherries are in agreement with data from the literature. For the mineral composition, the analyzed fruits presented lower concentrations of $\mathrm{P}, \mathrm{K}, \mathrm{Ca}, \mathrm{Mg}$ and $\mathrm{Zn}$ and higher levels of Fe. Furthermore, the values found for the bioactive compounds generally fit the ranges reported in the literature with the following minor differences: the phenolic content of the strawberry was higher than reported; the blackberry presented higher levels of flavonoids and raspberry was much lower than the literature; and the blackberry, strawberry and blueberry fruits showed lower anthocyanin contents than those found in the literature. The greatest difference was found in relation to ascorbic acid, as all fruits analyzed showed levels well above those found in the literature.

\section{References}

Acosta-Montoya, O., Vaillant, F., Cozzano, S., Mertz, C., Pérez, A. M., \& Castro, M. V. (2010). Phenolic content and antioxidant capacity of tropical highland blackberry (Rubus adenotrichus Schltdl.) during three edible maturity stages. Food Chemistry, 119, 1497-1501.

Almenar, E., Samsudin, H., Auras, R., Harte, B., \& Rubino, M. (2008). Postharvest shelf life extension of blueberries using a biodegradable package. Food Chemistry, 110, $120-127$.

AOAC-Association of Official Analytical Chemists (1998). Official methods of analysis of the Association of Official Analytical Chemists (Vol. 2, 16th ed.) Washington, DC.

Brand-williams, W., Cuvelier, M. E., \& Berset, C. (1995). Use of a free-radical method to evaluate antioxidant activity. Food Science and Technology, 28, 25-30.

Ballistreri, G., Continella, A., Gentile, A., Amenta, M., Fabroni, S., \& Rapisarda, P. (2012). Fruit quality and bioactive compounds relevant to human health of sweet cherry (Prunus avium L.) cultivars grown in Italy. Food Chemistry, 140, 630-638.

Benalti, M. J., Sabio, E., Hernández, M. T., \& Gervasini, C. (2003). Influence of storage delay on quality of 'Van' sweet cherry. Postharvest Biology and Technology, 28, 303-312.

Bobimaitè, R., Viskelis, P., \& Venskutonis, P. R. (2012). Variation of total phenolics, anthocyanins, ellagic acid and radical scavenging capacity in various raspberry (Rubus spp.) cultivars. Food Chemistry, 132, 1495-1501.

Campagnolo, M. A., \& Pio, R. (2012). Phenological and yield performance of black and redberry cultivars in western Paraná State. Acta Scientiarum. Agronomy, 34, 439-444.

Cekic, C., \& Ozgen, M. (2010). Comparison of antioxidant capacity and phytochemical properties of wild and cultivated red raspberries (Rubus idaeus L.). Journal of Food Composition and Analysis, 23, 540-544.

Chen, L., Xin, X., Zhang, H., \& Yuan, O. (2013). Phytochemical properties and antioxidant capacities of commercial raspberry varieties. Journal of Functional Foods, 5, 508-515.

Faniadis, D., Drogoudi, P. D., \& Vasilakakis, M. (2010). Effects of cultivar, orchard elevation, and storage on fruit quality characters of sweet cherry (Prunus avium L.). Scientia Horticulturae, 125, 301-304.

Haffner, K., Rosenfeld, H. J., Skrede, G., \& Wang, L. (2002). Quality of red raspberry Rubus idaeus L. cultivars after storage in controlled and normal atmospheres. Postharvest Biology and Technology, 24, 279-289.

Hakala, M., Lapvetelainen, A., Houpalahti Kallio, H., \& Tahvonen, R. (2003). Effects of varieties and cultivation conditions on the composition of strawberries. Journal of Food Composition and Analysis, 16, 67-80.

Hassimoto, N. M., Genovese, M. I., \& Lajolo, F. M. (2005). Antioxidant activity of dietary fruits, vegetables, and commercial frozen fruit pulps. Journal of Agricultural and Food Chemistry, 53, 2928-2935.

Hassimotto, N. M. A., Mota, R. V., Cordenunsi, B. R., \& Lajolo, F. M. (2008). Physicochemical characterization and bioactive compounds of blackberry fruits (Rubus sp.) grown in Brazil. Ciência e Tecnologia de Alimentos, 28(3), 702-708.

Jin, P., Wang, S. Y., Gao, H., Chen, H., Zhang, Y., \& Wang, C. (2012). Effect of cultural system and essential oil treatment on antioxidant capacity in raspberries. Food Chemistry, 132, 399-405.

Kafkas, E., Kosar, M., Paydas, S., Kafkas, S., \& Baser, K. H. C. (2007). Quality characteristics of strawberry genotypes at different maturation stages. Food Chemistry, 100, 1229-1236.

Koca, I., \& Karadeniz, B. (2009). Antioxidant properties of blackberry and blueberry fruits grown in the Black Sea Region of Turkey. Scientia Horticulturae, 121, 447-450.

Larrauri, J. A., Ruperez, P., \& Saura-Calixto, F. (1997). Effect of drying temperature on the stability of polyphenols and antioxidant activity of red grape pomace peels. Journal of Agricultural and Food Chemistry, 45, 1390-1393.

Marco, G. I. (1968). Rapid method for evaluation of antioxidants. Journal of the American Oil Chemists' Society, 45, 594-598.

Moura, P. H. A., Campagnolo, M. A., Pio, R., Curi, P. N., Assis, C. N., \& Silva, T. C. (2012). Fenologia e produção de cultivares de framboeseiras em regiões subtropicais no, Brasil. Pesquisa Agropecuária Brasileira, 47, 1714-1721. 
Pantelidis, G. E., Vasilakakis, M., Manganaris, G. A., \& Diamantidis, G. (2007). Antioxidant, capacity, phenol, anthocyanin and ascorbic acid contents in raspberries, blackberries, red currants, gooseberries and Cornelian cherries. Food Chemistry, 102, 777-783.

Ramful, D., Tarnus, E., Aruoma, O. I., Bourdan, E., \& Bahorun, T. (2011). Polyphenol composition, vitamin C content and antioxidant capacity of Mauritian citrus fruit pulps. Food Research International, 44, 2088-2099.

Re, R., Pellegrini, N., Proteggente, A., Pannala, A., Yang, M., \& Rice-Evans, C. (1999). Antioxidant activity applying an improved ABTS radical cation decolorization assay. Free Radical Biology e Medicine, 26, 1231-1237.

Salinas, Y. G., \& Garcia, R. (1985). Métodos químicos para elanálisis de suelosacidos y plantas forrajeras. Cali: Centro Internacional de Agricultura Tropical.

Santos, H. G., Jacomine, P. K. T., Anjos, L. H. C., Oliveira, V. A., Oliveira, J. B., Coelho, M. R., et al. (2006). Sistema brasileiro de classificação de solos (2nd ed.). Rio de Janeiro: Embrapa Solos.

Samec, D., \& Zegarac, J. P. (2011). Postharvest stability of antioxidant compounds in hawthorn and cornelian cherries at room and refrigerator temperaturesComparison with blackberries, white and red grapes. Scientia Horticulturae, 131, $15-21$.

Sharapin, N. (2000). Fundamentos de tecnología de productos fitoterapéuticos (Vol. 78). Convenio Andrés Bello.

Seeram, N. P. (2008). Berry fruits: Compositional elements, biochemical activities, and the impact of their intake on human health, performance, and disease. Journal of Agricultural and Food Chemistry, 56, 627-629.

Serradilla, M. J., Martín, A., Ruiz-Moyano, S., Hernández, A., \& López-Corrales, M. C. (2012). Physicochemical and sensorial characterisation of four sweet cherry cultivars grown in Jerte Valley (Spain). Food Chemistry, 133, 1551-1559.

Serradilla, M. J., Lozano, M., Bernalte, M. J., Ayuso, M. C., López-Corrales, M., \& González-Cómez, D. (2011). Physicochemical and bioactive properties evolution during ripening of 'Ambrunés' sweet cherry cultivar. Food Science and Technology, 44, 199-205.
Strohecker, R., \& Henning, H. M. (1967). Analisis de vitaminas: Metodos comprobados. Madrid: Paz Montalvo.

Tosun, I., Ustun, N. S., \& Tekguler, B. (2008). Physical and chemical changes during ripening of blackberry fruits. Science in Agriculture, 65(1), 87-90.

USDA-ARS (US Department of Agriculture, Agricultural Research Service) (2013) USDA nutrient database for standard reference, Release 25, Software 1.2.2, from the Nutrient Data Laboratory Page on the World Wide Web. <http:// www.nal.usda.gov/fnic/foodcomp>.

Vasco, C., Ruales, J., \& Kamal-Eldin, A. (2008). Total phenolic compounds and antioxidant capacities of major fruits from Ecuador. Food Chemistry, 111 816-823.

Wang, S, Y, \& Lin, H. S. (2000). Antioxidant activity in fruits and leaves of blackberry, raspberry, and strawberry varies with cultivar and developmental stage. Journal of Agricultural and Food Chemistry, 48, 140-146.

Waterhouse, A. L. (2002). Polyphenolics: Determination of total phenolics. In R. E. Wrolstad (Ed.), Current protocols in food analytical chemistry. New York: John Wiley \& Sons.

Wrolstad, R. E. (1976). Color and pigment analyses in fruit products. Bul 624. Oregon State 539 University Agriculture Experimental Station, Corvallis, OR.

Wu, R., Frei, B., Kennedy, J. A., \& Zhao, Y. (2010). Effects of refrigerated storage and processing technologies on the bioactive compounds and antioxidant capacities of 'Marion' and 'Evergreen' blackberries. Food Science and Technology, 43, $1253-1264$.

You, Q., Wang, B., Chen, F., Huang, Z., Wang, X., \& Luo, P. G. (2011). Comparison of anthocyanins and phenolics in organically and conventionally grown blueberries in selected cultivars. Food Chemistry, 125, 201-208.

Zhishen, J., Mengcheng, T., \& Jianming, W. (1999). The determination of flavonoid contents in mulberry and their scavenging effects on superoxide radicals. Food Chemistry, 64, 555-559. 